\title{
Towards A Theoretical Model Of The Impacts Of Incorporating Webcams In Virtual Teams
}

Joel Olson, PhD., Kaplan University, USA

Lynn Grinnell, PhD., St. Petersburg College, USA

Chad McAllister, PhD., Walden University, USA

Frank Appunn, PhD., University of Phoenix, USA

Kimberly Walters, PhD., Kaplan University, USA

\begin{abstract}
Virtual teams have proliferated over the last ten years as businesses realized benefits in coordinating across geographic and departmental boundaries. Studies of virtual teams, however, have revealed uneven success in team effectiveness. With the increase in quality and availability of video over the Internet, there are opportunities to improve effectiveness of virtual teams by integrating videoconferencing into synchronous meetings. The purpose of this qualitative study is to evaluate the impact of video on team interactions and effectiveness. Results showed a relationship between the added richness and authenticity brought about by video and increased effectiveness, while also showing a relationship between the increased stress of learning new technology and decreased effectiveness.
\end{abstract}

Keywords: Virtual Teams; Team Effectiveness; Communication; Technology; Video; Webcams

\section{INTRODUCTION}

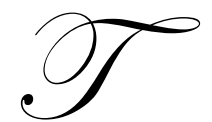

he popularity of teams to accomplish tasks once done by individuals or departments arose in the second half of the twentieth century with the Quality movement (Deming, 1986). The effectiveness of teams in business settings has been studied for several decades, both to validate the use of teams in various settings and to contend with the issues that arise within teams that reduce their effectiveness. Much has been written on the contribution of team types, size, motivation, and leadership, management of team conflict and trust, group dynamics, and stages of team development to the effectiveness of teams (Daim, 2011; Edison, 2007; Robbins \& Judge, 2010; Tuckman \& Jensen, 1977). As businesses increased their global reach, teams became a way to coordinate projects both cross-functionally and across geographic boundaries. These projects required substantial time, effort, and costs to complete using traditional methods of travel to face-to-face meetings. Dedicated teleconferencing systems began to be used to decrease travel costs while providing a semblance of meeting in person. These systems were often installed in a conference room and consisted of large monitors, video camera(s), and dedicated telecommunications hardware. While the systems could reduce travel, they were expensive to purchase and operate (Nash, 1986). With the advent of the Internet and personal computers, communication technology provided a tool for bringing dispersed teams together more frequently and at lower cost. Because of the obvious benefits to the bottom line, there has been growing interest and use of geographically dispersed virtual interactions to accomplish what face-to-face conferences did in the past. Geographic separation, time differences, and leanness of communication media can add to the friction within the team environment. The purpose of this study is to examine the impact of web-based video via webcams on virtual team interactions and effectiveness.

\subsection{LITERATURE REVIEW}

Research on virtual teams has been in the nascent stages for the last ten years. The literature on virtual teams often refers to characteristics that are common to traditional teams. Therefore, this section contains a brief 
review of the literature on traditional teams. It is also important to review virtual team definitions, typology, and issues proposed in the literature. Finally, trust and effectiveness, two constructs that have received attention in the literature, are specifically addressed and relevant to the study conclusions.

\subsection{Traditional teams}

Traditional teams that meet in face-to-face settings can be quality teams or quality circles, self-managed work teams, natural work teams, or cross-functional teams (Evans, 2005; Robbin \& Judge, 2010). Traditional teams became popular in the 1980s because of Deming's Total Quality Management (TQM) and Quality Circles (Deming, 1986). However, because teams were not always effective, considerable research was devoted to studying the qualities of effective teams. Team effectiveness can be derived from a number of factors, including work design, team composition, context, and team process (Campion, Paper, Medsker, 1996). While each of these areas is comprised of several characteristics (e.g., context includes resources, leadership, trust, and rewards), being successful in all aspects of the four-part team effectiveness model is not crucial to overall success. Typically, success may be measured by task completion, manager's ratings, and team satisfaction. Task completion and manager's ratings of teams and team members are quantitative measures; however, team satisfaction is more difficult to quantify. Team members can be satisfied with their accomplishments, their teamwork, or both, depending on the process used to solve problems (Grinnell, 2003). If they completed the task quickly without dissension, they tended to be satisfied with the outcome but not with the team. If they worked through conflict successfully, they tended to be satisfied with the team but not the outcome. If they used effective team facilitation to elicit buy-in for the proposed solution, they were satisfied with both.

Teams, whether face-to-face or virtual, can experience dysfunctionality from the lack of clear role expectations, power struggles, social loafing, and groupthink, among other issues (Robbins \& Judge, 2010 ). Role expectations can take the form of implicit psychological contracts (Rousseau, 1995), in which one or both parties makes assumptions based on past experience or perceived future that conflict when both are made explicit, or that create problems when changes occur in the organization that impact one party's implicit psychological contract. Power can become an issue in teams when one or more members of the team, whether the formal leader or not, exerts power through coercion or withholding information (Raven, 1993). Formation of coalitions within a team can also erode a leader's power (Stevenson, et al, 1985). Social loafing may arise from a lack of commitment to the team or a sense of a lack of equity among the task assignments (Comer, 1995). The dispersion of responsibility may also contribute to social loafing, as it may to groupthink (Peck, 1998). When the group is blamed for disappointing outcomes, individuals can, in their own minds, assign responsibility to the team rather than assuming responsibility themselves.

\subsection{Virtual teams}

A literature review on virtual teams summarized the characteristics of virtual teams as defined by over a dozen articles: "small, temporary groups of geographically, organizationally, and/or time-dispersed knowledge workers who coordinate their work predominantly with electronic information and communication technologies in order to accomplish one or more organizational tasks" (Ebrahim, Ahmed \& Taba, 2009, p. 2655). A typology proposed by Bell and Kozslowski (2002) identifies two key differences between conventional teams and virtual teams: dispersed locations and technology-aided communication. The more complex the task and the team, they suggested, the more that intensive communication channels would be needed to facilitate the teamwork. Complex tasks are those that require a high degree of interdependence to be completed successfully. Complexity is also related to the number of time zones, functions, cultures, and roles. More intensive communication channels included synchronous, video-enhanced channels, screen-sharing applications, and email support. Leadership, they suggest, also becomes more important when using virtual teams to attack complex tasks, especially when operating synchronously. Leaders should be prepared for degradation in team effectiveness in virtual teams, especially as teams and projects become more complex, and may have to spend additional time and effort building trust and a feeling of mutual obligation when trying to accomplish team goals.

Despite the cost and time advantages offered by virtual teams, many teams fail to live up to their potential (Greenberg, Greenberg, Antonucci, 2007). Three categories of issues can reduce effectiveness: communication issues, technology issues, and trust issues. 


\subsubsection{Communication issues}

Mehrabian's (1981) studies in the late 1960s identified a now-classic breakdown of verbal, tone, and nonverbal communication. He stated that people determine what they liked or disliked based on $7 \%$ verbal communication (i.e., words), 35\% vocal tone, and 55\% body language. In virtual teams, with technology stripping off layers of the richness of face-to-face communication, virtual communication can easily lead to misunderstandings (Ebrahim, et al., 2009). "Technology-enabled communication does not convey the same richness of emotion and reaction that face-to-face communication enables" (Greenberg, et al., 2007, p. 327). Adding richness to the communication channel through the use of video might permit team leaders to notice the combination of verbal and nonverbal behaviors, allowing them to diagnose potential problems more rapidly (Jones \& LeBaron, 2002). Team leaders can also use the context of individual work settings to facilitate communication. Jones and LeBaron suggest that further research is needed in the "interface of verbal and nonverbal behaviors and technological means of communication." (2002, p. 512)

\subsubsection{Technology issues}

There is an expectation that the more communication technology that is available, the better the team experience will be; however, when new technical capabilities are used within virtual teams, it has been noted that there is a significant initial drop in effectiveness, whether or not training was incorporated into the implementation (Ebrahim et al., 2009). In traditional teams, social loafing tends to occur when there is a lack of commitment or a sense of inequity (Comer, 1995). Technology adds a new dimension to "free riding" (Greenberg, et al, 2007) because distance removes team members from having to physically face each other. Multitasking is another issue that has arisen as a result of the improvement in technology (Bannister and Reminyi, 2009). Given the technological ability to work with multiple computer programs or monitors, and the physical rate of normal speech of 125 words/minute while the mind works at about 400 words/minute (Nichols, 1960), multitasking has proliferated in virtual communication (Benbunan-Fich \& Truman, 2009). Research conclusions are mixed in this, with some research supporting increased productivity with multitasking and other research showing it to be a major distraction, particularly when participants in the studies were multitasking with less-than-productive tasks (instant messages, video games, etc.)

\subsubsection{Trust in virtual teams}

Trust can be more challenging in virtual teams than traditional teams because of the lack of direct social pressure that comes from personal contact (Cascio, 2000; Handy, 1995). Jarvenpaa, et al. (2004, p. 251) said that "trust has direct positive effects on cooperation and performance" and Ebrahim, et al (2009), identified trust as a key element in successful virtual teams. Trust may become the primary determinant as to whether or not team members believe the project will be successful (Peters \& Karren, 2011). Although, even if trust is high in a team, it is not a reliable predictor of team effectiveness as research has shown no correlation between trust and team success (Jarvenpaa, et al., 2004).

It is interesting, however, to note that trust does not gradually develop, nor does it dissipate immediately upon disappointing performance (Iacano \& Weisband, 1997). Instead, trust in virtual teams seems to develop or change depending on the stage of virtual team development (Greenberg, et al., 2007). Virtual teams develop in five stages. Initially, swift trust can develop because of individuals' assumptions about their teammates (Daim, 2011). These assumptions are based on their own dispositions, their expectations about the institution, stereotyping, and sense of control. If a team member is introduced by a trusted colleague as trustworthy, the rest of the team is apt to accept the colleague's word regarding the team member's trustworthiness. If something were to happen (e.g., a task not being completed on time), members of the team may attribute the failure to external factors rather than untrustworthiness. During the organizing stage of virtual teams, trust seems to develop based on cognitive assessments - i.e., logical conclusions drawn from evidence. As the team develops and the team's focus changes from organizing tasks to accomplishing tasks, trust is based more on emotional and relational factors - i.e., affective trust. In contrast to the findings of Greenberg, et al., others have found that trust in virtual teams is built through performance (e.g., timely responses) rather than social interactions and emotional attachment, which are common when building trust in traditional teams (Peters \& Karren, 2011). 


\subsection{Effectiveness of virtual teams}

Traditional methods of monitoring team effectiveness by evaluating the inputs, processes, and outputs of the team may not be adequate for virtual teams (Bosch-Sijtsema, et al., 2011). Additional factors can impact the effectiveness of teams, including task content, team structure, team work processes, and workplace, among others, which may require additional focus for virtual teams because of the friction introduced by communication and technology issues. Task content can be creative or routine, ambiguous or clearly defined, and highly interdependent or independent. The more complex the task content, the more interaction is needed, making it likely that virtual teams will take longer accomplishing these tasks. Team structure can differ on size, geographic breadth, culture, organization, personality types, team tenure, knowledge, skills, and abilities, all of which can either support team success or increase team dysfunctionality, and all these characteristics are likely to be more diverse in virtual teams than in traditional teams. Team work processes can include collaborative skills, team competence, and performance monitoring. In virtual teams, these work processes can be enhanced by planning, communication and learning, and interpersonal activities that build trust and cohesion. Finally, the workplace has an impact on team effectiveness, whether it be the physical workspace, virtual workspace, or social workspace. Both virtual workspace, in which the primary team communication takes place, and social workspace, in which informal interactions build team cohesion, are particularly important to virtual teams; but the social workspace is often impoverished, to the detriment of team effectiveness.

If team effectiveness is defined (Kahai \& Cooper, 2003) in terms of decision quality, time required for decision-making, and consensus, then increasing media richness through the use of video conferencing should help in four ways: (1) adding multiple cues with the use of body language, (2) providing rapid feedback and clarification of meaning, (3) adding personal feelings and tailoring the communication to the needs of the recipient, and (4) language variety resulting from a wide range of symbols that can be used to convey meaning. This suggests that richer media, such as videoconferencing, should be more useful for tasks that are ill-defined and complex. Results of Kahai and Cooper's study, however, would indicate that richer media is not always relevant. Simpler media may be better when team members are not familiar with the task, as adding complex technology can add frustration. Richer media may be useful when the team leader is concerned with social loafing because it "enables multiple cues and immediate feedback [that] will result in greater total socio-emotional communication. Greater total (positive and negative) socio-emotional communication lends to increased task-oriented communication" (Kahai \& Cooper, 2003, p. 268).

\subsection{METHOD}

The study is exploratory in nature, using the Constant Comparative Method (CCM) based on grounded theory (Glaser and Strauss, 1967; Strauss, 1987; Glaser, 1992) to study in depth a specific autoethnographic case study (Ellis, Adams, and Bochner, 2011) of a virtual team of six people . It was conducted in a larger analysis context that applied mixed qualitative methods to address the issues of validity, reliability, and solidification. Two researchers with prior experience applying CCM collaborated on the analysis. CCM is the application of grounded theory, providing a structured and repeatable process (Boeije, 2002). For this case study, all data was collected from the subjects over a seven week period before analysis was conducted. Consequently the CCM was applied retrospectively, examining the data in time-order established by the subjects.

\subsection{Research objective}

Virtual teams are a significant development in the way organizations accomplish their work. Recent technological developments and their impact on the work of virtual teams is not fully understood. One such technological development is the increasing use of video webcams. This study sought to examine how the use of webcams influenced the work, interactions, and effectiveness of a virtual team.

\subsection{Subjects}

The subjects in the study were a virtual team consisting of six business faculty collaboratively working on research projects. The team consisted of five men and one woman operating in geographically separated locations 
in the United States. Prior to the start of the study, the team had met for approximately one hour weekly using a web conference tool that allowed the leader of the team to share video of himself via webcam and also provided a chat tool. All subjects interacted by phone and only the leader could be seen via video. This interaction created affiliation among the team members and became a suitable test bed for the introduction of webcams to determine their impact on an existing virtual team.

\subsection{Data collection}

The virtual team met for one hour each week to discuss and develop projects. Each subject created an audio log following the virtual team meetings to capture their reactions to the use of webcams in the meetings. The logs were structured around four topics:

1. What impact did video have on your team experience? Why?

2. What impact did video have on the development of trust in your virtual team? Why?

3. What impact did video have on your own effectiveness? The effectiveness of your team? Why?

4. Other comments.

Seven sets of logs were created for seven meetings, including an initial baseline before the virtual team began using webcams for all subjects and six weekly logs after the webcams were in use. The audio logs were independently transcribed and the CCM researchers provided with the transcripts.

\subsection{Data analysis}

ATLAS.ti software was used to manage the qualitative analysis of the transcripts. Consistent with the CCM approach, the transcripts were organized by subject by week so that codes were developed in time-order relevant to the transcripts. CCM was applied by thematically coding the logs in time order, refining and adding themes between each week of logs. For each set of logs, the following essential steps were used (Boeije, 2002):

1. Each researcher independently developed and applied thematic codes.

2. Researchers exchanged their code books and collaborated on differences, creating a unified codebook.

3. Each researcher re-applied the unified codebook to the logs.

4. Inter-coder reliability (ICR) was examined using Fleiss' Kappa as calculated by the Coding Analysis Toolkit ("CAT," 2010). ICR was used as a collaboration tool for discussing coding differences, not as a means for quantitatively assessing solidification (Marques \& McCall, 2005).

5. Researchers collaborated on improvements to the unified codebook in preparation for thematically coding the logs for the next week.

All seven sets of logs were analyzed in this manner, creating a final unified codebook, which was then reapplied to all logs in time-order by each researcher. Consequently, each researcher thematically coded each transcribed log a minimum of three times, refining and improving the codes iteratively.

Thematic coding of the subjects' logs resulted in the unified code book show in Table 1 with a total of 10 categories and 47 themes. Definitions for each theme were used by the researchers as the codes were applied.

During the coding process, the researchers found the trend of themes to be particularly interesting. Subjects were increasing, decreasing, or otherwise changing their focus regarding the impact webcams had on virtual team interactions over the seven weeks they logged their perceptions. For example, technical issues were encountered by most subjects as they initially used the webcam capabilities of the web conference system. One subject shared, "There was also some stress with learning about the technology, and then after I learned the technology, there's still a bit of stress in thinking about possible problems that might come up learning how to deal with technical issues in the future as they occurred." However, by Week 3 and thereafter subjects began sharing an increased comfort with the technology, such as, "Everyone is, I think, getting used to the tool and using the video tool pretty effectively and feeling more comfortable with it." 
Table 1

Summary of Coding Categories and Themes

\begin{tabular}{|c|c|}
\hline Category & Theme \\
\hline \multirow[t]{5}{*}{ Communications } & Communication-Added Richness \\
\hline & Communication-Decreased \\
\hline & Communication-Increased \\
\hline & Communication-Spontaneity \\
\hline & Communication-Unchanged \\
\hline \multirow[t]{4}{*}{ Connection/Authenticity } & Connection/Authenticity-Decreased \\
\hline & Connection/Authenticity_-Increased \\
\hline & Connection/Authenticity_-Location Issues \\
\hline & Connection/Authenticity_-Unchanged \\
\hline \multirow[t]{3}{*}{ Effectiveness } & Effectiveness-Decreased \\
\hline & Effectiveness-Increased \\
\hline & Effectiveness-Unchanged \\
\hline \multirow[t]{4}{*}{ Expectations } & Expectations-Low \\
\hline & Expectations-Positive-Satisfied \\
\hline & Expectations-Positive-Stated \\
\hline & Expectations-Positive-Unsatisfied \\
\hline \multirow{7}{*}{ Feelings } & Feelings-Disappointment \\
\hline & Feelings-Enjoyment-Decreased \\
\hline & Feelings_-Enjoyment-Increased \\
\hline & Feelings-Irritation \\
\hline & Feelings-Stress or Apprehension-Decreased \\
\hline & Feelings_-Stress or Apprehension-Increased \\
\hline & Feelings-Surprise \\
\hline \multirow[t]{5}{*}{ Focus } & Focus-Decreased \\
\hline & Focus-Increased \\
\hline & Focus-On Meeting Content or Purpose \\
\hline & Focus-Unchanged \\
\hline & Focus_-Video Norming Occurring \\
\hline \multirow[t]{4}{*}{ Moderating Factors } & Moderating Factors - Connection or Trust Already Existed \\
\hline & Moderating Factors - Other \\
\hline & Moderating Factors-Other Communication Modes \\
\hline & Moderating Factors-Personality Type \\
\hline \multirow[t]{5}{*}{ Technology } & Technology—Audio \\
\hline & Technology_-Issues/Limitations \\
\hline & Technology_Multiple Videos \\
\hline & Technology-Not a Factor \\
\hline & Technology-Single Video \\
\hline \multirow[t]{5}{*}{ Trust } & Trust-Actions to Build Trust \\
\hline & Trust-Decreased \\
\hline & Trust-Increased \\
\hline & Trust-Performance-based \\
\hline & Trust-Unchanged \\
\hline \multirow[t]{5}{*}{ Other } & Encouraging Tone \\
\hline & Image \& Perception \\
\hline & Learning Through Experience \\
\hline & Motivation, Preparation, and Conduct \\
\hline & Team Building \\
\hline
\end{tabular}

To identify such trends, the coding pattern of each theme was analyzed as a function of time by summing the quantity of instances a code was applied per log and then normalizing the quantity across all seven sets of timeordered logs. This resulted in patterns of themes not weighted by quantity of coding instances - the pattern is meaningful, not the number of instances of a code. To construct this analysis, the coding table was exported from ATLAS.ti to Excel the patterns visually constructed, shown in Figure 1. The small bar chart for each theme indicates the normalized instances of the theme occurring in each log progressing from the Baseline on the left through Week 6 on the right. Note that the first bar in the pattern is for the baseline logs before webcams where 
used by the entire team; only the leader of the virtual team was sharing video. All members of the virtual team used webcams during the team meetings starting in Week 1.

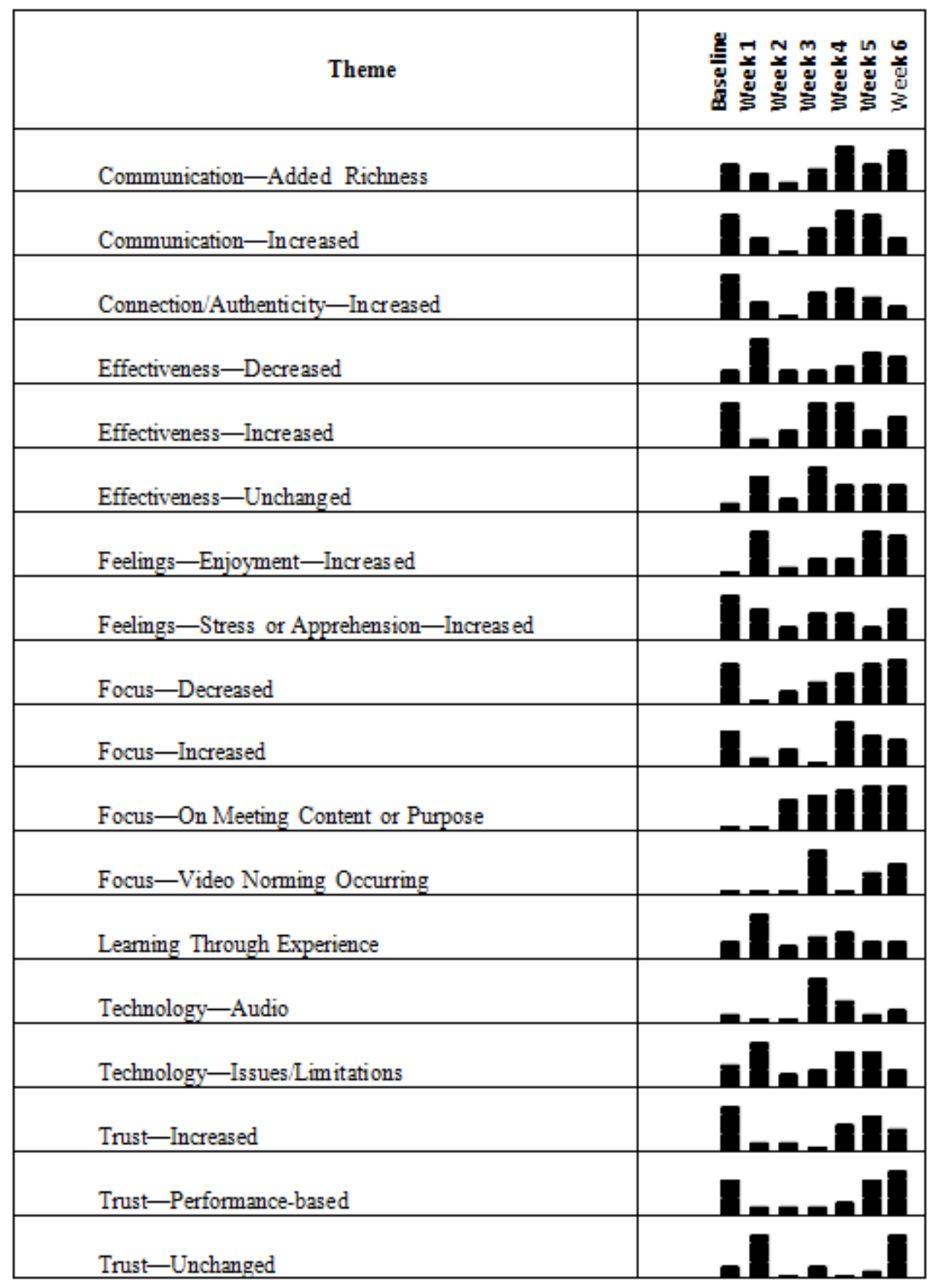

Figure 1. Patterns of themes based on normalized coding instances as a function of time

\subsection{DISCUSSION}

The following is a discussion of each theme shown in Figure 1. These themes were chosen due to the subjects' change in perceptions of each over the duration of the study timeframe. 


\subsection{Communication}

Added Richness conveyed the subjects' ability to use the video as an additional means to express themselves, allowing for more or different forms of creativity, added use of humor, and incorporation of body language. Video provided new ways to interact. The coding results for Added Richness showed that incorporating webcams was initially recognized by the virtual team as a benefit and remained a strong theme throughout all seven weeks. One subject summarized the value and potential of this added richness in week 7: "Again, the understanding of focus and are they really listening and did they understand that has some benefit, but I believe it could be improved dramatically if one were to include hand motions more than what we are in the team process." However, some subjects also shared an expectation to see more of a benefit from the addition of webcams than was initially realized, such as: "But I would say that for a first meeting, being able to see everyone did not meet my expectations for what was going to happen related to team trust and team effectiveness."

Increased Communication captured the subjects' perception that webcams increased communication effectiveness between team members. It provided a way to check for engagement and participation; to see if others look alert. Subjects shared: "I expected audio to be the primary means of communication and it was. But I found the video to be more important than I expected it to be. I think the primary impact of the video is on trust and not so much effectiveness" and "I was also surprised at how much people tell me. I think it's related to the video, because you can see people. You're more inclined to share personal things about your person when you can see people."

Connection/Authenticity was expressed by subjects as gaining a better sense about each other via the webcam video. They could see each other, where they worked, what they were wearing, and what their surroundings revealed about them. It created a degree of transparency and authenticity. The ability to establish relationships more quickly and deeply was attributed to the addition of video. One subject summarized this as, "So, I felt more connected to [Names] by seeing them - seeing their facial expressions, seeing their contexts, so I did feel more connected with them."

\subsection{Effectiveness}

Subjects shared their perceptions on individual and team Effectiveness with webcams integrated into virtual team meetings compared with their prior experience of not using webcams. Themes emerged from the subjects' transcripts to support Effectiveness Increasing, Decreasing, and remaining Unchanged. The trend patterns in Figure 1 show an expectation for team Effectiveness to increase, indicated by the Baseline bar. However, this drops considerably in Week 1 when webcams were first used by all members of the virtual team and Effectiveness decreased or remained unchanged. Subjects shared their experience in which using the unfamiliar webcam technology increased stress and decreased the team's prior effectiveness. For example, "I think I was so focused on understanding and using the technology that I was overwhelmed with an overwhelming amount of information and options and things to learn that I was focusing on learning the technology as opposed to capitalizing on working with the visual features, as well." The technology became the focus instead of the purpose of the meeting. This subsided in Week 2 with net effectiveness increasing: "The perception of team effectiveness was greater, and I hope that we can develop that as we go forward" and "And also effectiveness because I think we're getting through questions and brainstorming a little bit more easily by being able to see reactions to statements on video."

By Week 4 all three dimensions of Effectiveness, Increasing, Decreasing, and Unchanged were again high, indicating very mixed perceptions. Some of this was due to subjects being self-reflective on their journey with webcams as they had become more comfortable with using them: "One conclusion to draw from this experience is technology, in the beginning stages, will hurt team effectiveness." Another element that surfaced was that, as the team became comfortable with the webcam technology in Weeks 1, 2, and 3, they began incorporating other capabilities of the web conference tool in Week 4, such as desktop sharing. Introducing these additional unfamiliar capabilities impacted effectiveness. One subject shared this issue, which was echoed by others, in Week 5: "I guess one of the things that disappointed me is that the technology does sometimes get in the way of effectiveness because you have to manipulate more tools rather than fewer tools." The complexity of the virtual team tools had a strong perceived impact on effectiveness. 


\subsection{Feeling}

The first aspect of feelings was Enjoyment Increased, which captures the theme that feelings of enjoyment, comfortableness, satisfaction, wellness and the like increased as a result of using webcams. An increase in enjoyment occurred when the webcams were initially introduced but less enjoyment was expressed the next week as technology and learning issues dominated perceptions: "I would have felt or I had hoped that video would have allowed the meeting to flow better and not have pauses and uncertainty as people waited for others to communicate." However, as experience with the webcams increased, the consensus was that they improved the enjoyment associated with virtual team meetings. Example expressions of this include: "I'm enjoying seeing the folks on the team" and "So, instead of the team meetings being dreaded or to be avoided, I find them to be more attractive and anticipated."

Another frequently shared feeling was an increase in Stress or Apprehension. This was conveyed as increased stress from unfamiliar or problematic technology or trying something new and not knowing the potential impacts. As might be expected, stress was initially high as seen in the Baseline bar in Figure 1 in anticipation of using webcams and remained high during their initial use in Week 1. Comments such as, "I was supposed to lead the meeting and I was a novice with the technology" and "...it's gonna be a learning curve for us to move forward but once I think we overcome and accomplish week one, get through this stage fright of this new technology, I think we'll be okay" reflect this concern. As they became more comfortable with the technology, stress related to the technology element of using the webcams had become a non-issue for all subjects by Week 5 and remained that way in Week 6. The webcams were offering value to the interaction and the technology was not getting in the way, as expressed by this subject in Week 5: "I think that what the visual feedback does for me is it helps me to relax more." The subjects had learned to use the tool and the tool was no longer a stumbling block. The increase in stress seen in Figure 1 in Week 5 and 6 is related to other factors, such as the introduction of screen sharing to the virtual team meeting: "I felt a bit anxious about that effectiveness because I wasn't confident in my use of the sharing of the screen." Also, there were some expressions that being seen by others could or did increase stress when feeling ill or not being prepared to be seen.

\subsection{Focus}

One of the more frequently shared themes was an increase in Focus or a decrease in multitasking as a result of using webcams. Attentiveness and engagement were also perceived as improving. In previous virtual team meetings that did not use webcams, subjects shared that they were more likely to have multitasked and be working on other things when meeting by phone. The addition of webcams made team members self-conscious about being perceived as being engaged in the meeting: "If I look at the video impact on my own actions, I was aware that people might feel that I'm not being attentive, and I felt obliged to show that I was attentive in the video" and "Feeling during the conference - awareness of my participation and communication capabilities, not unlike a physical meeting." Focus--Decreased in Figure 1does show a rise in the frequency of subjects addressing decreased focus in weeks 2 through 6 , but this was attributed to self-reflection in the subjects' logs regarding the ability of video to reduce multitasking and create more focus. For example, subjects shared: "If it was just the audio, then I would be multitasking and doing something else and not be connected to what the speaker was saying," "If they were not present, if they were obviously distracted, then I would have shifted my focus and begun to ask more specific questions - not to put them on the spot or embarrass them, but rather specific questions to begin to engage them more in the process," "So, I've been in phone conference calls where I'm not sure they're very effective because I'm not sure people are really engaged."

A new theme clearly emerged during Week 2 and grew in its use that was not previously seen. This is a Focus On Meeting Content or Purpose, defined as the subjects addressing the purpose of the meeting or content related to the meeting and not the phenomenon under study. This may be an indication that the use of video had become expected and natural and subjects were more focused on their purpose for meeting. Along with this was the introduction of the Video Norming Occurring theme that was first observed in Week 3. As the team members became comfortable with the webcam technology and its use, it appeared to be taking a back seat to the purpose of the meetings. It was discussed less in the logs, being replaced with information about the meeting topics. This was particularly interesting because team members stopped answering or reduced their focus on answering the study's questions, choosing instead to focus on content of the team's agenda. 
Video also appeared to increase focus by reducing multitasking. The leader made several references expressing concern over multitasking when no video was present: "The visual component, also, I think, increased how interesting the meeting was. I thought that it would help the team to focus or do some multitasking if they felt like they were interacting with an individual and that visual image then would capture their attention and keep them focused on the discussion and prevent being involved in multitasking - so it'd limit multitasking or reduce multitasking" and "So, a couple team members don't say as much, so it's good to be able to see them visually because then I know they're engaged. If I couldn't see them, then they might be multitasking or focusing on other responsibilities." Subjects identified a sense of self-consciousness when tempted to multitask: "I was more conscious of that multitasking with the video, whereas, when I multitask - when I'm not on video, I just turn my mike off and type."

\subsection{Learning through experience}

The use of unfamiliar technology and its associated capabilities presented initial obstacles to the virtual team. Subjects improved in their use of the technology as their experience with it increased. For the most part, learning through experience followed the path of the power law of learning with subjects reporting rapid improvements in their use of technology (Palmieri, 1999). Initially, subjects felt effectiveness was diminished, but by Week 3 most team members felt the learning curve had been overcome:

- Week 1: "I was hampered and diminished by the new technology and the learning curve involved with the new technology."

- Week 2: "I am still with everyone else, still learning the process, not all effective as a view of the technology."

- Week 3: "The use of technology was somewhat better."

- Week 4: "It actually went pretty smoothly, and I think we're all getting kind of used to using the technology, and things are going well."

- Week 6: "I believe that the technology disadvantages or mastery is now behind us."

While most team members reported significant gains in learning through experience, it was not universally consistent. One member stated: "I think using the technology once a week doesn't facilitate comprehension or utilization. For myself, I would need to use the tool more often or more frequently in order to be more effective and efficient in capitalizing on the opportunity of [the web conferencing tool]." Also, not all functions had been covered in initial meetings, causing the learning curve to restart when new functions were introduced. As one member recommended: "One should consider four meetings if one doesn't prepare for all the functions to come through."

\subsection{Technology}

The importance of Audio was expressed in contrast to the video by being the most important communication media. Video adds an element of communication richness, but the audio is vital. As an example, a subject shared, "First prize is audio plus video, but it is not as much better as audio over text." However, the use of webcams was seen as a means of enhancing communication for the previously phone-based virtual team meetings: "I don't hear as good though when I don't have the visual feedback."

Technology Issues/Limitations included issues such as poor lighting, background noise, not knowing the user interface well, and encountering technology problems. All of these issues were viewed as diminishing the team experience. It is important to note that the limitations highlighted by subjects were sometimes the result of subjects not understanding how to use the technology. Additional training could have minimized the occurrence of perceived limitations. There was recognition that using technology well was related to its value and impact on team interactions. Learning to effectively use the technology was a large aspect of the first meeting that utilized webcams, as seen in the spike in Figure 1 for Issues/Limitations during Week 1. One subject said, "I was not disappointed in the first session, but felt that technology had not been fully utilized yet, and that is to be expected with limited preparation and no special equipment." While many subjects were more comfortable with the technology by Week 3, some were not, such as the subject who shared, "So, I don't think the video had much of an impact on effectiveness. If anything, it might've been distracting in effectiveness because I'm still learning how to 
use the video function." However, comfort with the webcam technology did greatly increase from Week 1 to Week 3. There were new Issues/Limitations encountered in Weeks 4, 5, and 6 related to desktop sharing and other factors, not predominantly from the webcams.

\subsection{Trust}

Trust Increased represents the theme that trust between team members increased as a result of incorporating the video in team interactions. An example mentioned by one team member was the ability to look someone in the eye via the webcams. Subjects shared in their Baseline logs an expectation for the webcams to positively contribute to trust. This was not initially realized as technology issues and learning to use the webcams became a hindrance. Subjects instead indicated that the addition of webcams during Week 1 had little impact on trust, such as, "I didn't sense that the presence of increased video diminished or increased that sense of trust." In Weeks 4, 5, and 6, after gaining some experience with using webcams, their impact on trust was seen as more positive. One subject shared, "In terms of trust, I think it very well could actually help to nurture trust because the body language communicates different messages that I don't see otherwise." However, there was also strong recognition that the webcams themselves do not create trust. Rather, trust is built when team members follow through on commitments and do the work that is expected ("I think the greatest factor for trust was followthrough"). To the extent that video increases Connection/Authenticity, it can increase the responsibility and pressure felt by team members to fulfill their commitments.

\subsection{FINDINGS AND RELATIONSHIPS IN THEMES}

The subjects' logs indicated co-occurrence between themes. The data analysis also showed relationships between variables. Three dominate relationships are further discussed below. The first two are in relationship to the added richness of the communications enabled by using webcams and includes increases in authenticity, effectiveness, and focus. The third is the relationship between technology issues, stress, and effectiveness. The topics examined here are an extension of the analysis previously shared and the definitions of each theme appeared previously.

\subsection{Communication and connection/authenticity}

Communication-Added Richness and Connection/Authenticity-Increased were frequently expressed in relationship to each other by the subjects. The addition of webcams to the virtual meetings added richness to the communication channel, in part due to body language and seeing people in their environment, which increased the connection subjects felt with each other (Greenberg, et al., 2007). Subjects shared: "...the inclusion of body language causes me to see everyone in a different way," "I think the video helped to increase that sense of intimacy because I could see people," "That actually helps me personally to develop the relationship, to feel closer, to feel, as I mentioned, more relaxed, and more able to not fake to be engaged because I really can see what's going on," and "The video warms up the team meeting, adds some texture, some flavor, some color - literally it does because you can see people and their environments and what they're wearing."

\subsection{Communication, effectiveness, and focus}

A dependency between Communication-Added Richness, Effectiveness-Increased, and Focus-Increased was well supported in the data. Co-occurrence analysis was first performed to examine the relationship between the added communication richness enabled by using webcams and individual and team effectiveness (Jones \& LeBaron, 2002). However, the dominate reason provided for an increase in effectiveness was the accountability video added for subjects to be engaged in the meeting and not multitask (Benbunan-Fich \& Truman, 2009). Unlike virtual meetings without video, subjects felt they could not multitask without it being detected by their teammates. Consequently, effectiveness was increased because of an increase in focus (decrease in multitasking) provided by the added richness of the communication channel.

This was expressed in several ways by subjects, including: “... it did have an impact on my effectiveness just by being able to see others...," "And also effectiveness because I think we're getting through questions and 
brainstorming a little bit more easily by being able to see reactions to statements on video," " ... it did create a higher level of effectiveness at least on my part as far as the teamwork was concerned because I did not feel that I could type without people noticing me type," and "It occurs to me that the control or the commitment to the meeting is increased by video, and while it isn't obvious, it would make sense that by forcing participants to provide more attention than a traditional remote meeting that productivity could improve."

\subsection{Learning new technology, stress, and effectiveness}

Learning new technologies is a source of stress for many people. This was prevalent in the data as the technology associated with the use of webcams was unfamiliar to most subjects. This had two related consequences. First, subjects expressed increased stress initially as a result of adding webcam technology to the virtual team meetings. The stress was primarily associated with learning (Bosch-Sijtsema, 2007) and properly using the technology, however there was also some initial image consciousness concerns also. Second, the need to learn the webcam technology caused a decrease in team effectiveness (Kimble, 2011). Time during the virtual team meetings was spent resolving technical issues and subjects helping each other learn to use the video tools. These relationships are evident in the following quotes from subjects:

- There was also some stress with learning about the technology, and then after I learned the technology, there's still a bit of stress in thinking about possible problems that might come up learning how to deal with technical issues in the future as they occurred.

- $\quad$... I was still really focused on not making mistakes; I didn't have a sense of freedom with the technology. I felt limited by the technology.

- I felt a bit awkward during the conference, and not because of the video images, but because of how new and unfamiliar it was.

- $\quad$ It seemed like we were doing all this extra technology and extra complexity without much yield or much payoff.

- $\quad$ I think I was so focused on understanding and using the technology that I was overwhelmed with an overwhelming amount of information and options and things to learn that I was focusing on learning the technology as opposed to capitalizing on working with the visual features, as well.

Once the subjects had learned the basics of using webcams during their virtual meetings, stress associated with technology issues declined and effectiveness increased (Ebrahim et al., 2009). Comfort increased after the first meeting using webcams and stress due to using the webcam technology was not identified by subjects after the third meeting.

\subsection{Proposed Theoretical Model}

A theoretical model is suggested from the analysis of the data (Figure 1) and the key relationships in the themes. Authenticity and experience with technology both contribute to team effectiveness. Authenticity is increased as a result of incorporating video, supporting the development of trust; however, this does not appear to affect team effectiveness as much as expertise with the communication technology used by the team. Initially, a lack of expertise in technology can interfere with team effectiveness and also cause an increase in individual stress. The technology learning curve is generally steep, depending on the complexity of the capabilities. Within a relatively short period of time (approximately three virtual team meetings in our observations) team effectiveness attains a level at which the focus of the team is on the team task. At that point, the team can work effectively and benefits from the increase in focus. As is typical with a qualitative study, these findings cannot be generalized and further study is needed to test the applicability of this model to other virtual teams incorporating video. 


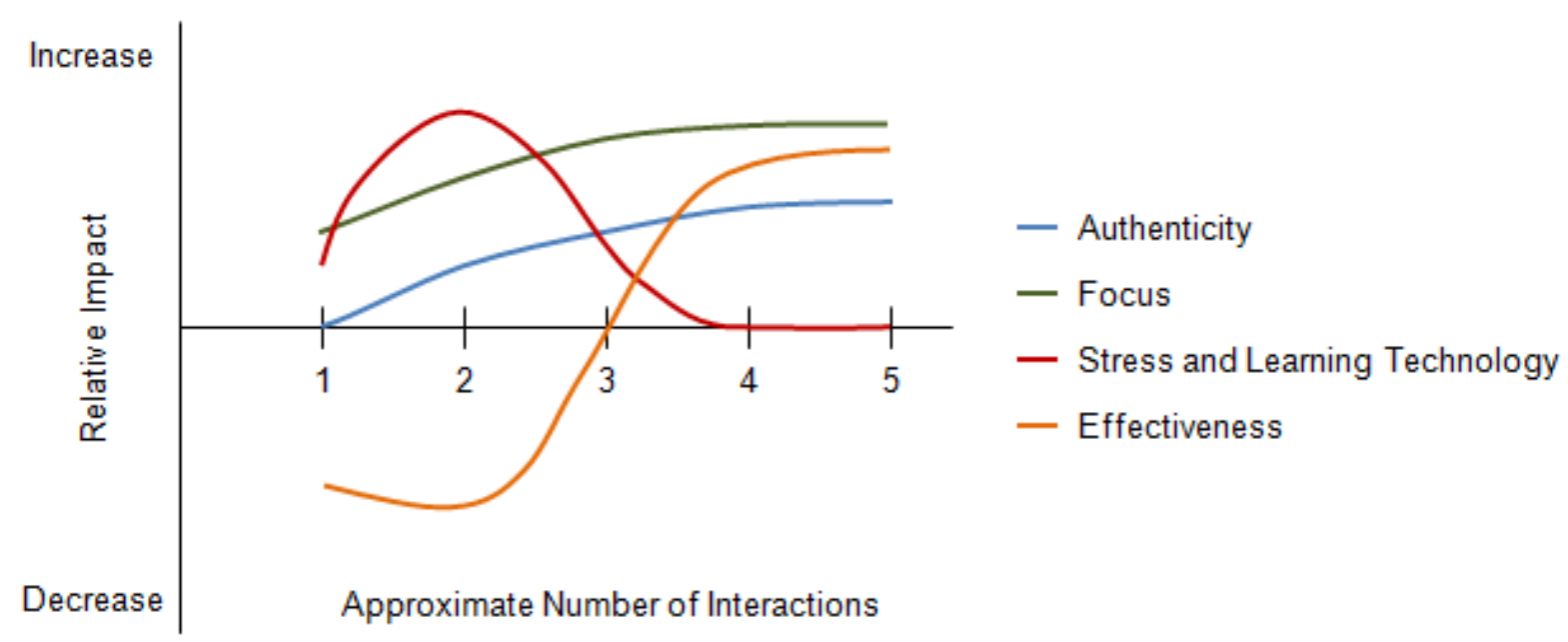

Figure 2: Proposed theoretical model for effect of video on virtual team development.

\subsection{CONCLUSION}

Incorporating webcams in virtual meetings had beneficial outcomes with few detriments. The added richness of communication provided by seeing the meeting participants had a positive impact. Body language could be interpreted, visual humor used, and other visual cues incorporated (Ebrahim, et al., 2009). Closely associated with this increase in communication depth was the added connection subjects felt with each other and an increase in authenticity. These factors also indicated a positive association with an initial increase in trust. While trust may be improved initially through the addition of webcams, it was not a strong factor in the overall functioning of the team as the ability to fulfill commitments was viewed as much more important. Participating in virtual team meetings was more enjoyable for subjects, and meetings became something to look forward to. Also, subjects were more focused on the work of the meetings instead of multitasking during the meetings. The increase in focus and communication richness were closely associated with an increase in individual and team effectiveness.

A negative aspect of adding webcams to virtual team meetings was an initial decrease in productivity. Meeting time was expended on helping team members understand how to use the webcam technology. Being unfamiliar with the technology also caused some apprehension by subjects to participate in the meetings initially as well as increased stress. After one to two meetings most subjects were comfortable with the technology, and stress associated with the use of webcams decreased. This suggests that virtual teams choosing to adopt webcams should be purposeful in preparing team members for the experience (Bosch-Sijtsema, 2007). This includes providing the proper technology (e.g, HD webcams, noise cancelling headsets), learning to use the technology's capabilities, considering limitations and likely issues that may arise, and addressing image consciousness concerns (Kimble, 2011). Based on the experience of the subjects in this study, we expect one or two short training sessions focused on these items would more quickly improve the effectiveness of virtual teams adopting webcam technologies.

\section{AUTHOR INFORMATION}

Joel Olson, $\mathrm{PhD}$ in Human Resources from the College of Education, Colorado State University, Ft. Collins and an MA in theology from Denver Seminary, has extensive experience in nonprofit leadership and consultation, education, and instructional design. Most recently, he has served the Reformed Church in America and the Evangelical Presbyterian Church as a consultant for churches in crisis. Currently he serves as the Leadership and Management Academic Department Chair for the School of Business and Management in Kaplan University. E-mail: jolson@kaplan.edu.

Lynn Grinnell, Professor, holds a PhD from the University of South Florida in Curriculum and Instruction and an M.S. in Organization Business Management. She has published on sustainability management, educational 
measurement, and teams. Her research examines the ethical influence of individuals and teams and measurement of learning. E-mail: grinnell.lynn@ @spcollege.edu. Corresponding author.

Chad McAllister is lead faculty at Walden University in the DBA Program and holds a PhD from Capella University in Organization and Management with previous degrees in electrical engineering. His research interests involve issues in new product development and innovation, including virtual team performance. He serves as VP of Education for the Rocky Mountain Product Development and Management Association chapter. E-mail: chad.mcallister@waldenu.edu.

Frank Appunn, Professor, holds a PhD from Capella University in Organization, Management, and Technology. He has published on technology, information security, and teams. His research considers the confluence of technology, people, and organizations, while information assurance forms another interest area. He teaches at multiple institutions, leads a leadership degree and specialist areas include technology, security, business, and project management, and is the chair of 20 doctoral dissertation committees. E-mail: Frank@ Appunn.net.

Kimberly Walters is a Professor of Human Resources at Kaplan University and has a $\mathrm{PhD}$ in Industrial and Organizational Psychology. Her research interests include examining the relationship between trust and effectiveness in virtual workers and studying reality based learning in the online classroom. She serves the University as a course curriculum leader and as a faculty advisor for the SHRM Student Chapter. E-mail: kwalters@kaplan.edu.

\section{REFERENCES}

1. Bannister, F. and Remenyi, D., (2009). Multitasking: The uncertain impact of technology on knowledge workers and managers. The Electronic Journal Information Systems Evaluation 12 (1), 1 - 12.

2. Bell, B. and Kozlowski, S. (2002). A typology of virtual teams: Implications for effective leadership. Group \& Organizational Management, 27, 14-49.

3. Benbunan-Fich and Truman, G. (2009). Multitasking with laptops during meetings. Communications of the ACM, 52 (2), 139-141.

4. Boeije, H. (2002). A Purposeful Approach to the Constant Comparative Method in the Analysis of Qualitative Interviews. Quality and Quantity, 36(4), 391-409.

5. Bosch-Sijtsema, P. (2007). The impact of individual expectations and expectation conflicts on virtual teams. Group \& Organizational Management, 32, 358-388.

6. Bosch-Sijtsema, P., Fruchter, R., Martiainen, M., and Ruohomaki, V. (2011). A framework to analyze knowledge work in distributed teams. Group \& Organizational Management, 36, 275-307.

7. Campion, M., Papper, E., and Medsker, G. (1995). Relations between work team characteristics and effectiveness: A replication and extension. Personnel Psychology, 49(2), 429-452.

8. $\quad$ CAT. (2010). Retrieved from http://cat.ucsur.pitt.edu/default.aspx.

9. Comer, D. (1995). A model of social loafing in real work groups. Human Relations, 48(6), 647-667.

10. Daim, T., Ha, A., Reutiman, S., Hughes, B., Pathak, U., Bynum, W., Bhatla, A. (In press). Exploring the communication breakdown in global virtual teams, International Journal of Project Management.

11. Deming, W. Edwards (1986). Out of the Crisis. MIT Press.

12. Ebrahim, N., Ahmed, S., and Taba, Z. (2009). Virtual teams: A literature review. Australian Journal of Basic and Applied Sciences. 3(3), 2653-2669.

13. Edison, T. (2008). The team development life cycle: A new look. Defense AT\&L, 37(3), 14-17.

14. Ellis, C., Adams, T., and Bochner, A. (2011). Autoethnography: An overview. Forum: Qualitative Social Research, 12 (1), 10. Retrieved from: http://www.qualitativeresearch.net/index.php/fqs/article/view/1589/3095.

15. Evans, J. (2005). Total quality: Management, organization, and strategy, $4^{\text {th }}$ ed. Mason, OH: SouthWestern.

16. Glaser, B. G. and Strauss, A. L. (1967). The Discovery of Grounded Theory: Strategies for Qualitative Research. Chicago: Aldine.

17. Glaser, B. G. (1992). Emergence vs. Forcing. Basics of Grounded Theory Analysis. Mill Valley. 
18. Greenberg, P., Greenberg, R., and Antonucci, Y. (2007). Creating and sustaining trust in virtual teams. Business Horizons, 50, 325-333.

19. Jarvenpaa, S., Shaw, T., and Staples, D. (2004). Toward contextualized theories of trust: The role of trust in global virtual teams. Information Systems Research, 15 (3), 250-267.

20. Jones, S. and LeBaron, C. (2002). Research on the relationship between verbal and nonverbal communication: Emerging integrations. Journal of Communication, 52(3), 499-521.

21. Kahai, S. and Cooper, R. (2003). Exploring the core concepts of media richness theory: The impact of cue multiplicity and feedback immediacy on decision quality. Journal of Management Information Systems, 20 (1), 263-299.

22. Kimble, C. (2011, January). Building effective virtual teams: How to overcome the problems of trust and identity in virtual teams. Global Business and Organizational Excellence, 30(2), 6 -15.

23. Marques, J., and McCall, C. (2005). The application of interrater reliability as a solidification instrument in a phenomenological study. The Qualitative Report, 10, 439-462.

24. Mehrabian, A. (1981). Silent messages: Implicit communication of emotions and attitudes. Belmont, CA: Wadsworth.

25. Nash, Peter. (1986). Now -- Conferencing by Video Link. Industrial Management + Data Systems, 86 (9/10), $12-13$.

26. Nichols, R. (1960). What can be done about listening? The Supervisor's Notebook, 22 (1).

27. Palmieri, T. (1999). Theories of automaticity and the power law of practice. Journal of Experimental Psychology. 25 (2), 543-551.

28. Peck, M. S. (1998). People of the lie: The hope of healing human evil. Austin: Touchstone.

29. Peters, L. and Karren, R. (2009). An examination of the roles of trust and functional diversity on virtual team performance ratings. Group \& Organizational Management, 34, 479-504.

30. Raven, B. (1993). The bases of power: Origins and recent developments. Journal of Social Issues, 49, $227-$ 251.

31. Robbins, S. and Judge, T. (2010). Organizational Behavior. Upper Saddle River, NJ: Prentice-Hall.

32. Rousseau, D. (1995). Psychological contracts in organizations: Understanding written and unwritten agreements. Thousand Oaks, CA: Sage.

33. Stevenson, W., Pearce, J., and Porter, L. (1985). The concept of 'coalition' in organizational theory and research. Academy of Management Review, 10(2), 261-263.

34. Strauss, A. L. (1987). Qualitative Analysis for Social Scientists. Cambridge: Cambridge University Press.

35. Tuckman, S. and Jensen, M. (1977). Stages of small group development revisited. Group and Organizational Management, 2, 419-427. 
NOTES 